\title{
Estimation of mechanical property degradation of poly(lactic acid) and flax fibre reinforced poly(lactic acid) bio-composites during thermal processing
}

Hossein Mohammad Khanlou ${ }^{\mathrm{a}}$, Peter Woodfield ${ }^{\mathrm{a}}$, John Summerscales ${ }_{2}^{\mathrm{b}}$ Gaston Francucci ${ }^{\mathrm{c}}$, Benjamin King ${ }^{\mathrm{a}}$, Sepehr Talebian ${ }^{\mathrm{d}}$, Javad Foroughi ${ }^{\mathrm{d}}$, Wayne Hall ${ }^{\mathrm{a}}$

${ }^{\text {a }}$ Griffith School of Engineering, Gold Coast Campus, Griffith University, Queensland 4222, Australia

${ }^{\mathrm{b}}$ Advanced Composites Manufacturing Centre, School of Engineering, Reynolds Building, University of Plymouth, Plymouth, Devon PL4 8AA, United Kingdom

${ }^{\mathrm{c}}$ National University of Mar del Plata, Research institute of materials science and technology (INTEMA-CONICET)

${ }^{\mathrm{d}}$ ARC Centre of Excellence for Electromaterials Science, AIIM Facility, University of Wollongong, NSW, Australia

\begin{abstract}
Thermal degradation and chemical degradation are among the key issues affecting mechanical properties and ultimately utilization of natural fibre reinforced polymer (NFRP) bio-composites. In our previous work, mathematical models were used to identify thermal processing boundaries and to recognize an optimized window for NFRP bio-composites. In this study, a correlation relating the tensile strength of flax/PLA bio-composite to the processing temperature history is proposed. For the first time, an existing linear model, which corresponds to the tensile strength of natural polymers and their degree of polymerization, has been combined with reaction kinetics to predict the tensile strength of NFRP biocomposites as a function of processing temperature history. In addition, a non-linear model has been proposed which shows a significant improvement for longer periods of time, compared with the linear model. The model is based on the underlying thermo-chemical degradation processes occurring during manufacture of NFRP bio-composites. The model is capable of predicting the tensile strength of the bio-composite within $10 \%$ error.
\end{abstract}

Keywords: Bio-polymer composites; Chemical degradation; Degree of polymerization; Natural fibres; Mechanical properties; Thermal degradation

\author{
Abbreviations \\ acrylated epoxidised soybean oil (resin) \\ (AESO) \\ carbon fibre $(\mathrm{CF})$ \\ circular cross-sectional area (CSA) \\ degree of polymerization (DP) \\ fibre area correction factor (FACF) \\ glass fibre (GF) \\ natural fibre reinforced polymer (NFRP) \\ non-woven (NW)
}

\author{
poly (lactic acid) (PLA) \\ poly (propylene) (PP) \\ plain weave $(\mathrm{PW})$ \\ rules-of-mixture (RoM) \\ unidirectional (UD) \\ v/o (fibre) volume percentage \\ w/o (fibre) weight percentage
}




\section{Introduction}

Thermal degradation is one of the main challenges in the manufacture of NFRP biocomposites, when a thermal processing method is used [1, 2]. Unlike carbon and glass fibre composites where the fibre is robust to composite manufacturing temperature, natural fibres degrade quickly when exposed to temperatures as low as $160^{\circ} \mathrm{C}$ [3], $180^{\circ} \mathrm{C}$ [4], $180-190^{\circ} \mathrm{C}$ [1] or $180-200^{\circ} \mathrm{C}$ [5]. Bio-matrices also suffer a similar problem in comparison with synthetic polymers [2, 6-8]. Compression molding is a common method in which setting an appropriate temperature (e.g. $170-200^{\circ} \mathrm{C}$ ) and consolidation time play an important role in achieving the ultimate mechanical properties of the produced bio-composite. Many studies have manufactured bio-composites at various temperatures (e.g. $160-220^{\circ} \mathrm{C}$ ) and various consolidation times (e.g. 2-20min) and as a result have demonstrated the sensitivity of the mechanical properties to the thermal history during manufacture of NFRP bio-composites [17]. In particular, the effects of chemical reactions (molar mass changes) are responsible for degradation of mechanical properties of both matrix and fibre during the thermal processing [9-13]. Indicative process conditions from the literature are given in Table 1, which shows the effect of temperature and other factors on freshly manufactured bio-composites.

An important gap in the literature is in connecting the degradation of mechanical properties of bio-materials to the thermochemical degradation that occurs during manufacture. There are a few works in the literature which have tried to investigate the relationship between mechanical properties and the number-average molecular weight of polymers or fibres [9-13]. In 1945, Flory [9] demonstrated a linear relationship between the number average molecular weight and the tensile strength of a blend composed of a mixture of cellulose acetate fractions. In 2014, Rasselet et al. [10] also tried to link the molar mass of oxidised PLA polymer to its mechanical properties. They concluded that the reduction of mechanical properties is linked to molar mass reduction during the oxidation process. In addition, mechanical properties (tenacity) of fibres have been shown to reduce along with decline in molar mass [12]. To fill the gap, this paper considers molar mass degradation or reduction in degree of polymerisation as a critical indicator of the extent of thermochemical degradation making it possible to determine the rate of deterioration of mechanical properties for both matrix and fibre. Data produced from the proposed models can be used in prediction or optimising mechanical properties of bio-composites. For the first time, this study has brought the thermochemical degradation concepts together with the models which have been used for composites to predict the tensile strength of NFRP bio-composites after thermal processing. 
Table 1. Indicative process conditions for pressing bio-composites

\begin{tabular}{|c|c|c|c|c|c|c|c|c|c|c|}
\hline Fibre & $\begin{array}{c}\text { Fibre } \\
\text { Orientation }\end{array}$ & $\begin{array}{c}\text { Fibre } \\
\text { fraction } \\
(\%)\end{array}$ & Matrix & $\begin{array}{c}\text { Pressure } \\
(\mathrm{MPa})\end{array}$ & $\begin{array}{c}\text { Temperature } \\
\left({ }^{\circ} \mathrm{C}\right)\end{array}$ & $\begin{array}{l}\text { Time } \\
(\min )\end{array}$ & $\begin{array}{l}\text { Young } \\
\text { modulus } \\
(\mathrm{GPa})\end{array}$ & $\begin{array}{c}\text { Tensile } \\
\text { strength } \\
(\mathrm{MPa})\end{array}$ & $\begin{array}{c}\text { Tensile } \\
\text { strain at } \\
\text { failure }(\%)\end{array}$ & Reference \\
\hline ramie & - & 35 w/o & PP & 2 & 185 & 10 & - & 42.8 & - & [14] \\
\hline ramie & - & $30 \mathrm{v} / \mathrm{o}$ & PLA & 20 & 170 & 4 & - & 52 & 3.2 & [6] \\
\hline jute & - & $40 \mathrm{w} / \mathrm{O}$ & PP & 0.5 & 180 & 2 & $\approx 3.5$ & $\approx 27$ & - & [15] \\
\hline jute & UD & 40 w/o & PLA & 3.3 & $\begin{array}{c}180-220 \\
\text { and } 60\end{array}$ & $\begin{array}{c}3-10 \\
\text { and } 1\end{array}$ & - & $\approx 100$ & 1.6 & [1] \\
\hline kenaf & UD & 40 w/o & PLA & 4.2 & 180 & 20 & 7.1 and 4.2 & $\begin{array}{c}52.9 \text { and } \\
24.1\end{array}$ & $\begin{array}{c}1.05 \text { and } \\
0.76\end{array}$ & [4] \\
\hline kenaf & UD & $70 \mathrm{v} / \mathrm{o}$ & PLA & 10 & 160 & 10 & $\approx 23$ & $\approx 220$ & - & [16] \\
\hline kenaf & $\mathrm{NW}$ & $30 \mathrm{w} / \mathrm{o}$ & $\mathrm{PP}$ & 5 & 250 & 15 & $\approx 1.6$ & $\approx 40$ & - & [17] \\
\hline flax & - & $\begin{array}{c}10-30 \\
\text { w/o }\end{array}$ & PLA & 18 & 170 & 5 & $3.9-6.3$ & $42-54$ & - & [2] \\
\hline flax & NW & 50 w/o & PLA & 5 & $\begin{array}{l}180 \\
190 \\
200\end{array}$ & $\begin{array}{c}5 \\
10 \\
15\end{array}$ & $\approx 8-10$ & $\begin{array}{l}\approx 65-80 \\
\approx 77-60 \\
\approx 72-56\end{array}$ & - & [5] \\
\hline flax & PW & $60 \mathrm{w} / \mathrm{o}$ & AESO & 4 & 160 & 5 & 32 & 280 & - & [3] \\
\hline hemp & - & $40 \mathrm{w} / \mathrm{O}$ & PP & 0.4 & 180 & 2 & $\approx 7$ & $\approx 52$ & - & [15] \\
\hline hemp & - & $\begin{array}{c}30-64 \\
\text { w/o }\end{array}$ & PP & 8.3 & 200 & 5 & - & $15-26$ & $3.6-9.3$ & [18] \\
\hline hemp & UD & $40 \mathrm{w} / \mathrm{o}$ & PLA & 4.2 & 180 & 20 & 8 & 57 & 1.24 & [4] \\
\hline hemp & - & $30 \mathrm{w} / \mathrm{o}$ & PLA & 1.7 & 195 & 20 & 6 & 45 & - & [7] \\
\hline hemp & - & $30 \mathrm{w} / \mathrm{o}$ & $\mathrm{PP}$ & 1.7 & 195 & 20 & 4 & 25 & - & [7] \\
\hline
\end{tabular}




\section{Theoretical Background and considerations}

This section reviews degradation and mechanical property models that are appropriate for composite manufacturing and can potentially be used to account for thermochemical degradation of NFRP bio-composites.

\subsection{Temperature/time dependent mechanical properties}

To manufacture composites by compression moulding, the temperature of the hot press should be sufficiently above the melting point of the polymer to lower the matrix viscosity and the time sufficiently long for penetration of the melt into the fibres achieving a strong bond between matrix and fibre [19]. However, mechanical properties of natural fibres and thermoplastic matrices are degraded even at low temperatures and short holding times [19, 20]. In particular, poly (lactic acid) (PLA) suffers from thermal degradation for temperatures that typically occur during the compression moulding process [21-23]. A number of studies have also indicated that the moulding time has a significant effect on the mechanical properties of compression-moulded PLA-based bio-composites [4, 5, 7, 16, 24-26]. Thus, in this study the purpose is to determine the tensile strength and modulus of the matrix, fibre and composite as a function of processing temperature history.

\subsection{Thermo-chemical degradation of matrix (depolymerisation via chain scission)}

The temperature of the hot press causes chemical reactions within the matrix material leading to a decrease in the average length of polymer chains tending towards an equilibrium value [21-23]. A reduction of the degree of polymerization $(D P)$ is a main indicator for polymer thermal degradation at high temperature and is prominent in polymers with acidic end groups such as PLA [27, 28]. Since there is strong correspondence between mechanical properties and polymer length it is appropriate to propose Eqs. (1) and (2) where the mechanical properties are simply a function of the degree of polymerization which itself is a function of the temperature history:

$$
\begin{aligned}
& E_{x}=E_{x}\left(D P_{x}(T, t)\right) \\
& \sigma_{x}=\sigma_{x}\left(D P_{x}(T, t)\right)
\end{aligned}
$$

where subscript $x$ is $m$ for matrix in this context, or $f$ for fibre at $\S 2.3$, and $D P$ is given by Eq. (3) [19]:

$$
D P_{x}=M_{n-a v g} / m_{0}
$$

where $M_{n \text {-avg }}$ is the number-average molar mass of polymers in the matrix and $m_{0}$ is the molar

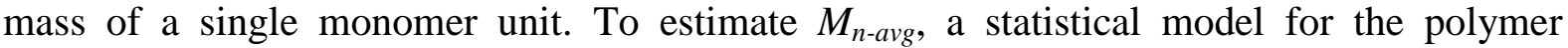
considered both degradation and recombination reactions which occur during the thermal processing as proposed by Wachsen [22] and revised by Yu et al. [23] and Khanlou et al. [8].

For the thermo-chemical degradation of the PLA matrix [8], 


$$
\frac{d \lambda_{0}}{d t}=k_{x d}\left(\frac{\rho}{m_{0}}-\lambda_{0}\right)-\frac{k_{x c} \lambda^{2}}{2}
$$

where $\rho$ is the density, $k$ is the effect of temperature on the reaction with subscript $c$ for (re)combination and subscript $d$ for degradation, and $\lambda_{0}$ is the total number of moles of molecules per unit volume,

$$
\lambda_{0-\text { initial }}=\rho / M_{n-\text { start }}
$$

The effect of temperature on (re-)combination and degradation $\left(k_{\mathrm{xc}}\right.$ and $k_{\mathrm{xd}}$ in Eq. (4)) is expressed using the Arrhenius equation (Eq. (6)) [19]:

$$
k_{x y}=A_{x y} \exp \left(\frac{-E_{a x y}}{R T}\right)
$$

where subscript $y$ is $c$ for (re-)combination or $d$ for degradation, $A_{x y}$ are the pre-exponential factors $\left(\mathrm{s}^{-1}\right)$ and $E_{a x y}$ are the apparent activation energies, $R$ is the universal gas constant $(8.3136 \mathrm{~J} / \mathrm{mol} \mathrm{K})$ and $T$ is the temperature $(\mathrm{K})$. It is assumed that the same values of $k_{x c}$ and $k_{x \mathrm{~d}}$ apply to polymers of any length. Table 2 shows the values for kinetic parameters and initial conditions for modelling polymer degradation of PLA, which are calculated or extracted from the literature [8,21]; and Fig. 1 shows changes of DP of PLA at various temperatures and times.

To calculate $\lambda_{0}$ for isothermal processing conditions, an analytical solution, Eq. (6), was developed by separating the variables [8]:

$$
\lambda_{\mathrm{o}}=\frac{-k_{d}}{k_{c}}+\frac{\sqrt{2 k_{c} k_{d} \lambda_{1}+k_{d}^{2}}}{k_{c}} \tanh \left(\frac{(t+C) \sqrt{2 k_{c} k_{d} \lambda_{1}+k_{d}^{2}}}{2}\right)
$$

where $C$ is defined by the initial condition for $\lambda_{0}$ as:

$$
C=\frac{2}{\sqrt{2 k_{c} k_{d} \lambda_{1}+k_{d}^{2}}} \tanh ^{-1}\left(\left(\lambda_{0-\text { initial }}+\frac{k_{d}}{k_{c}}\right) \frac{k_{c}}{\sqrt{2 k_{c} k_{d} \lambda_{1}+k_{d}^{2}}}\right)
$$

where $\lambda_{1}$ is the total number of moles of monomer units per unit volume:

$$
\lambda_{1}=\rho / m_{0}=\text { constant }
$$

Table 2. Kinetic parameters and initial conditions for modelling polymer degradation of PLA

\begin{tabular}{cccccccc}
\hline $\begin{array}{c}A_{c} \\
(\mathrm{~L} / \mathrm{mol} / \mathrm{s})\end{array}$ & $\begin{array}{c}E_{a c} \\
(\mathrm{~kJ} / \mathrm{mol})\end{array}$ & $\begin{array}{c}A_{d} \\
\left(\mathrm{~s}^{-1}\right)\end{array}$ & $\begin{array}{c}E_{a d} \\
(\mathrm{~kJ} / \mathrm{mol})\end{array}$ & $\begin{array}{c}m_{0} \\
(\mathrm{~g} / \mathrm{mol})\end{array}$ & $\begin{array}{c}M_{n \text {-start }} \\
(\mathrm{g} / \mathrm{mol})\end{array}$ & $\begin{array}{c}\text { Start } \\
\text { Polydispersity }\end{array}$ & $\begin{array}{c}\text { Density } \\
(\mathrm{g} / \mathrm{L})\end{array}$ \\
\hline 121.6 & 37.7 & 1600 & 79 & 72.07 & $1.06 \times 10^{5}$ & 1.87 & 1260 \\
\hline
\end{tabular}




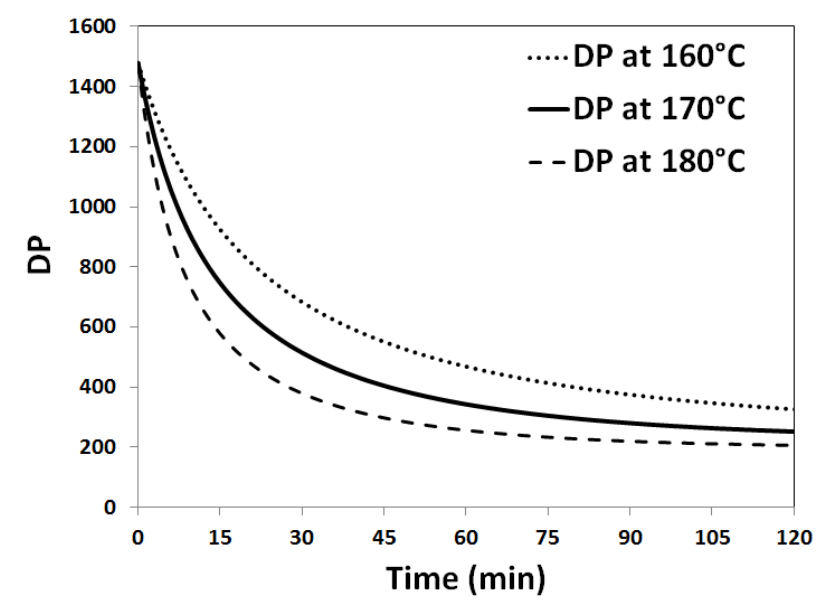

Fig. 1. DP progress of PLA at various temperatures and times

\subsection{Thermo-chemical degradation of natural fibres (degree of polymerization of natural fibres)}

Natural fibre cellulosic chains also show scission behaviour when they are exposed to a high temperature, in a similar way to polymeric matrices. Gassan et al. correlated the tenacity (mechanical) properties of jute and flax fibres at various temperatures to $D P$ [12]. Now assuming the fibre modulus and strength are each a function of $D P$, we can use Eqs. (1), (2) and (3) with subscript $x=f$ (fibre).

A parameter $N$ related to the molecule concentration $(N \equiv 1-(1 / D P))$ can be predicted using a first-order chemical rate equation as shown by Testa et al. [29] to estimate the chain scission of cellulosic materials. Their model corresponds to the random chain scission of bonds in a linear chain polymer:

$$
\frac{d N}{d t}=K \times N
$$

and using Eq. (6) again with subscript $x$ in the equation now being $f$ (fibre degradation). For a given temperature, Eqs. (6) and (10) may be solved to give:

$$
N=N_{0} e^{t A_{f j} \exp \left(\frac{-E_{a f j}}{R T}\right)}
$$

In a study by Gassan et al. [12], $D P$ was measured after heating flax fibre for different periods of time for three different temperatures as listed in Table 1 . The initial value given for $D P_{0}$ was 1505 . For the present study, a least-squares fitting procedure was used to determine the pre-exponential factor $\left(A=-0.178 \mathrm{~s}^{-1}\right)$ and the apparent activation energy $\left(E_{a}=50.5 \times 10^{3}\right.$ $\mathrm{J} / \mathrm{mol}$ ) to fit Eqs. (3), (6) and (10) to the data given in Table 3 [19]. Fig. 2 shows changes of $D P$ progress of flax at various temperatures and times. 
Table 3. DP of flax fibre heat treated for three time periods and at three temperatures [12]

\begin{tabular}{l|lll}
\hline & \multicolumn{3}{|c}{$D P$} \\
\hline Time (min) & $170{ }^{\circ} \mathrm{C}$ & $190{ }^{\circ} \mathrm{C}$ & $210{ }^{\circ} \mathrm{C}$ \\
\hline 40 & 866 & 509 & 387 \\
120 & 511 & 360 & 261 \\
\hline
\end{tabular}

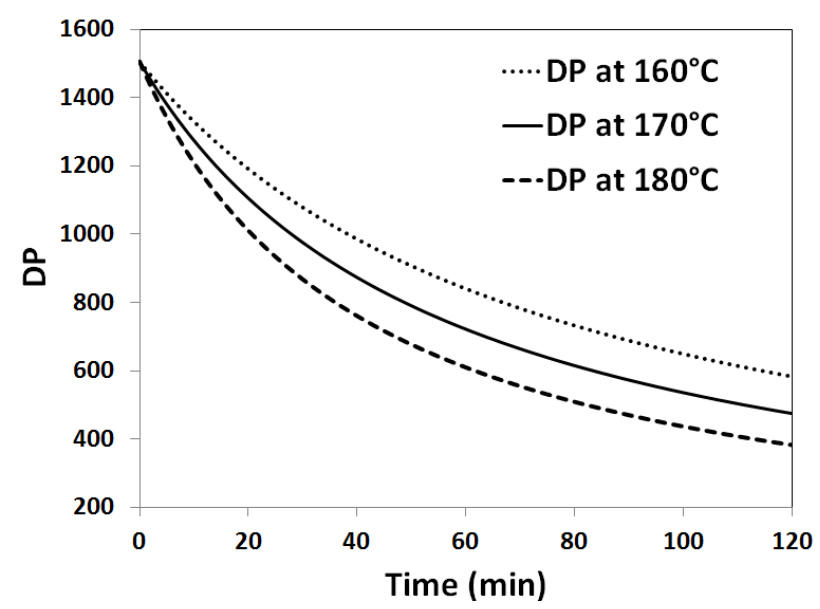

Fig. 2. $D P$ progress of flax at various temperatures and times

\subsection{Rule of mixture for mechanical properties prediction}

The prediction of composite material properties normally uses a rule-of-mixture (RoM) to estimate the moduli and axial strength. It is a parallel spring model based on the assumption that fibres and matrix will experience equal strain under loading in the fibre direction. It is assumed that the fibres can be anisotropic with different mechanical properties in the axial and transverse (radial) directions, while the matrix is isotropic [30]. Eqs. (12) and (13) [30] have recently been developed specifically for NFRP bio-composites:

$$
\begin{aligned}
& E_{c}=\kappa \eta_{\mathrm{d}} \eta_{\mathrm{l}} \eta_{\mathrm{o}} V_{\mathrm{f}} E_{\mathrm{f}}+E_{\mathrm{m}} V_{\mathrm{m}} \\
& \sigma_{c}=\kappa V_{\mathrm{f}} \sigma_{\mathrm{f}}+V_{\mathrm{m}} \sigma_{\mathrm{m}} \text { (for UD composites on the principal axis) }
\end{aligned}
$$

where $E$ is the elastic modulus (using Eq. (1) here), $V$ is the volume fraction, $\kappa$ is a fibre area correction factor (FACF) (used when properties have been derived using an assumption of circular cross-sectional area (CSA) but fibres do not have circular CSA, $\eta_{\mathrm{d}}$ is the fibre diameter distribution factor, $\eta_{1}$ is the fibre length distribution factor, $\eta_{\mathrm{o}}$ is the fibre orientation distribution factor, $\sigma$ is the strength (using Eq. (2) here), $\sigma_{\mathrm{m}}{ }_{\mathrm{m}}$ is the stress in the matrix at the failure strain of the fibre and subscripts $c, f, m$, are composite, fibre and matrix, respectively. Eqs. (12) and (13) predict that the composite properties will increase with increasing fibre 
volume fraction/percentage $(v / o)$ [25, 31-33]. The fibres play an important role as carriers of load and stress, for example, stiffness and strength [34-37].

\subsection{Mechanical properties in relation to degree of polymerization}

The objective here is to consider the connection between the chemical degradation and tensile properties of bio-composites. Thus, as discussed above, we found that mechanical properties are dependent on $D P$, and in particular it has been reported that tensile strength is in a linear relationship with $1 / D P[9]$ :

$$
\sigma=a_{0}-\frac{a_{1}}{D P}
$$

where $a_{0}$ and $a_{1}$ are constants which can be determined empirically from experimental data.

\section{Experiment}

Ultimately we are interested to predict tensile properties of a flax/PLA bio-composite manufactured using the compression moulding process. For this purpose, the similar methods of manufacturing and mechanical properties examinations to our previous work were carried out [19]. Unidirectional (UD) flaxply fabric ( $180 \mathrm{~g} / \mathrm{m}^{2}$ flax) manufactured by Lineo Company (France) was used in this study. PLA film (25 microns thick) was supplied by Magical Film Enterprises Co. Ltd. (Taiwan) [19].

Polymer molecular weight and polydispersity were measured using gel permeation chromatography (GPC) on a Shimadzu 20A system equipped with refractive index detector (RID-10A). Analysis was performed at $35^{\circ} \mathrm{C}$ using a Styragel HT 4 column $(7.8 \times 300 \mathrm{~mm})$ obtained from Waters, Co (Miliford, MA) in isocractic conditions using tetrahydrofuran (THF) as solvent with a flow rate of $1.0 \mathrm{ml} / \mathrm{min}$.

To find the sensitivity of mechanical properties of the bio-composite to various processing conditions, mechanical properties of a flax/PLA bio-composite were measured for different temperatures and processing times. Six consolidation times were considered with 16 samples tested for each consolidation time. Fig. 3 shows the tensile properties of flax/PLA composite at the six consolidation times. The moduli can be seen to be sensibly independent of consolidation time (in the range from 28.2 to $29.9 \mathrm{GPa}$ based on the initial slope of the stressstrain curve), but the tensile strength and fracture strain reduce significantly as the consolidation time increases (from 276 to $155 \mathrm{MPa}$ and 2 to $1.2 \%$ respectively). 


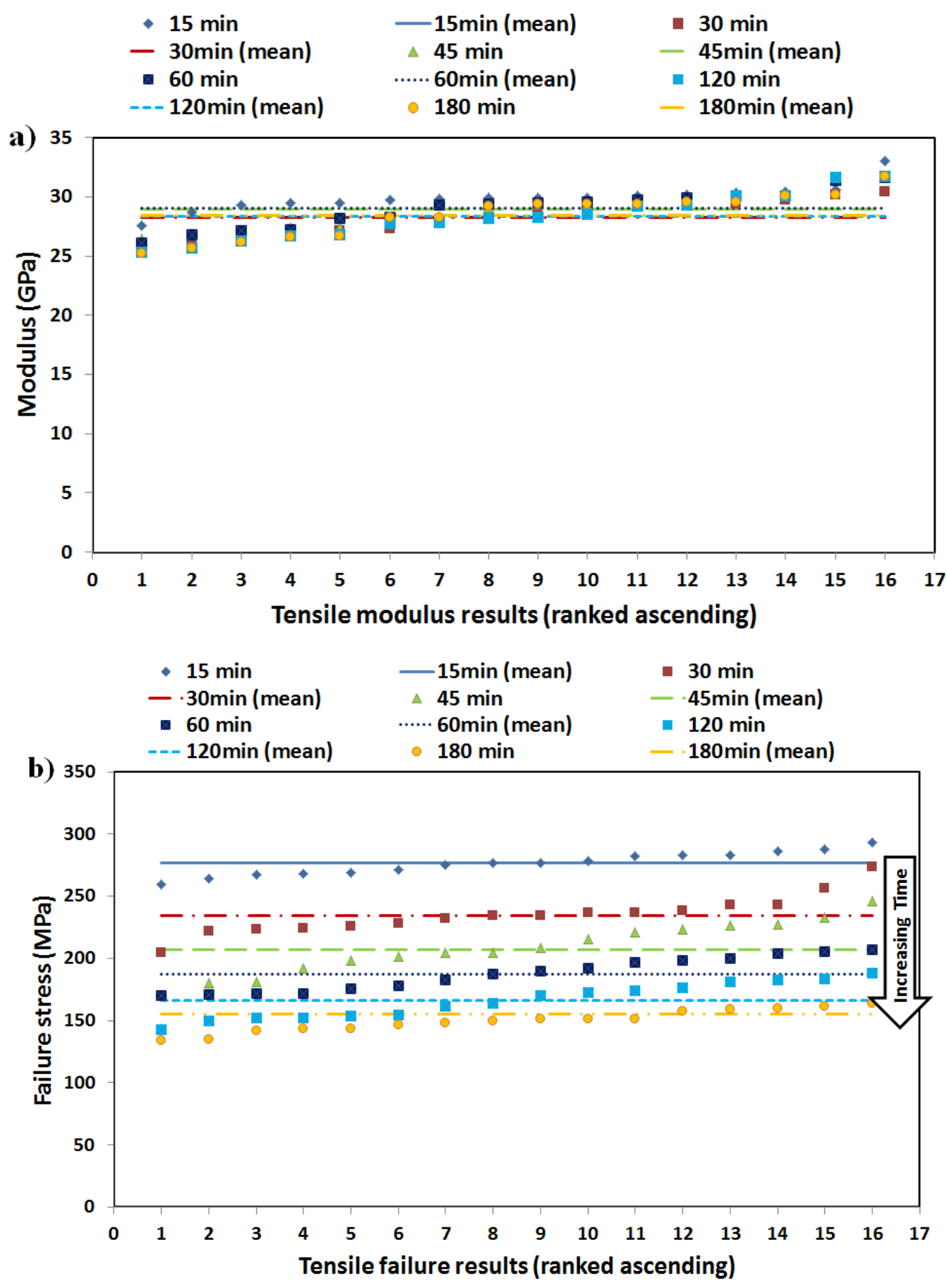




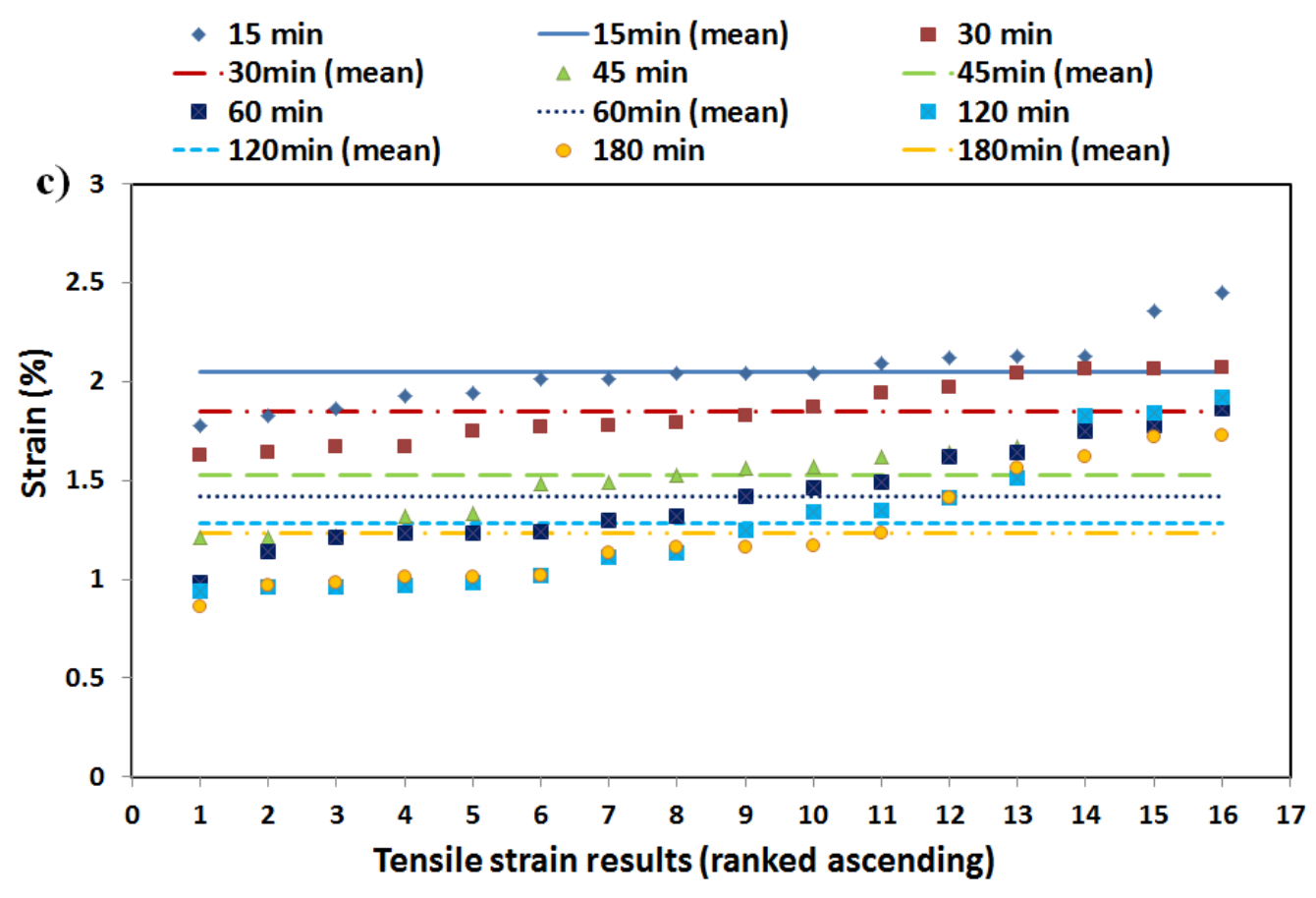

Fig. 3. Mechanical properties of flax/PLA composites: (a) Modulus; (b) Tensile strength; and (c) Failure strain.

\subsection{Modelling and prediction of the tensile properties of PLA}

Since the changes of tensile modulus are insignificant, we have considered Eq. (1) to be independent of the temperature history. To predict tensile strength of PLA Eq. (14) has been applied as:

$$
\sigma_{\text {matrix }}=a_{0-\text { matrix }}-\frac{a_{1-\text { matrix }}}{D P}
$$

To find $a_{0 \text {-matrix }}$ and $a_{1 \text {-matrix }}$, the tensile strength is plotted against $1 / D P$ graph (Fig. 4) resulting in $a_{0 \text {-matrix }}=67 \mathrm{MPa}$, and $a_{1 \text {-matrix }}=1.8 \times 10^{4} \mathrm{MPa}$. In Fig. 4, tensile strengths of PLA were achieved through experiments in this study and $1 / D P$ values of the reported temperatures/times are calculated using Eq. (3). Moreover, the initial trend of tensile changes of PLA (Fig. 4) is similar to the linear changes reported by Flory [9]. A better fit to the measured data could be obtained using an equation in the form:

$$
\sigma_{\text {matrix }}=A \exp (-B / D P)+C
$$




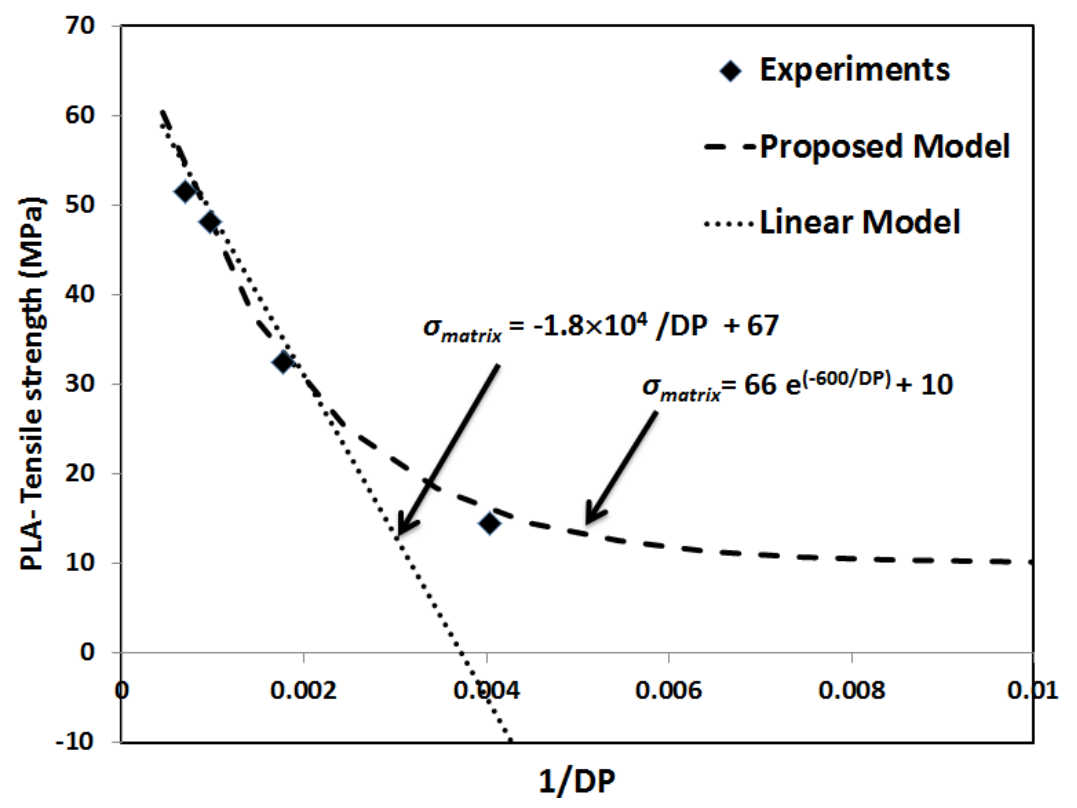

Fig. 4. Tensile strength vs $1 / D P$ for PLA at various temperatures and times. $D P$ for PLA was measured using gel permeation chromatography (GPC).

\subsection{Calculation and prediction of the tensile strength of fibres}

To find $a_{0 \text {-fibre }}$ and $a_{1 \text {-fibre }}$ for Eq. (17), we need to calculate the tensile strength of fibre using a RoM (Eq. 13), when parameters are: $\kappa=1.35$ (which is half of apparent diameter) [38], $V_{\mathrm{f}}=0.48, V_{\mathrm{m}}=0.52$, experimental tensile strengths of the bio-composite, $D P$ of matrix, $D P$ of fibre, and calculated tensile strengths of matrix at various conditions, which are presented in Table 4. In Fig. 5, 1/ DP values for the fibre at various temperatures/times are calculated using Eqs. (3), (6) and (15). Subsequently, the tensile strengths of fibre using the linear model and proposed model are achieved (see Table 4). As a result, $a_{0-\text { fibre }}=560 \mathrm{MPa}$ and $a_{1-\text { fibre }}=-$ $2.1 \times 10^{5} \mathrm{MPa}$ are achieved using the linear model.

$$
\sigma_{\text {fibre }}=a_{0-\text { fibre }}-\frac{a_{1-\text { fibre }}}{D P}
$$

Similar to PLA, the data could be better correlated using:

$$
\sigma_{\text {fibre }}=A \exp (-B / D P)+C
$$




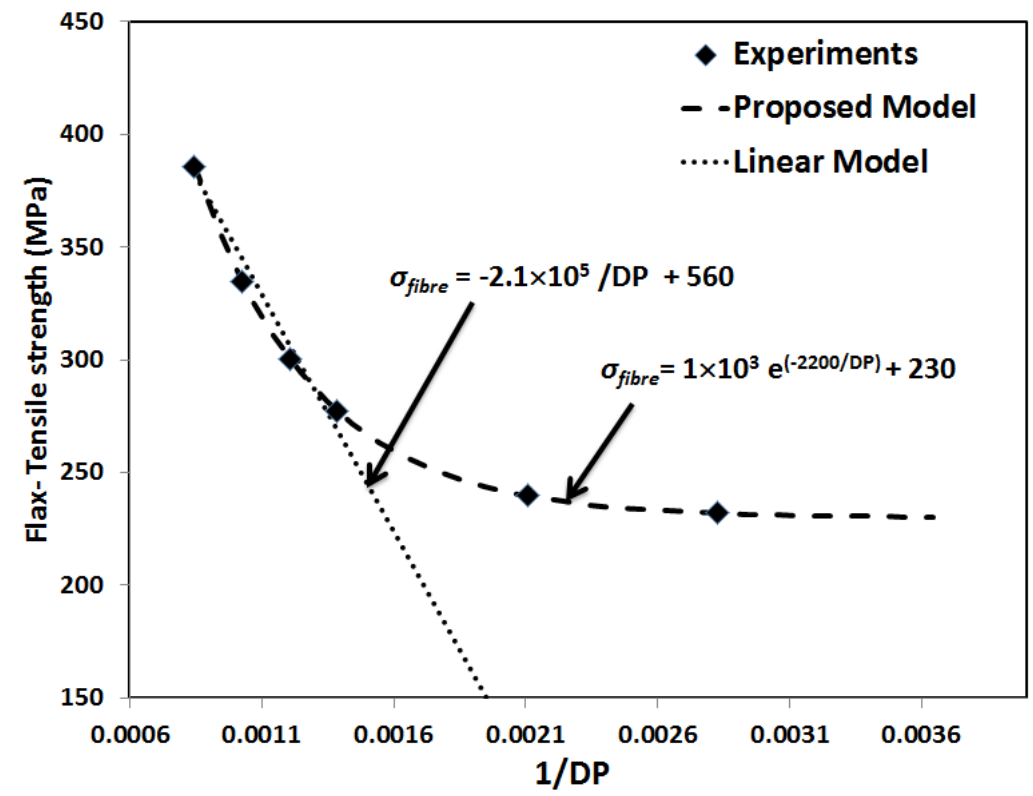

Fig. 5. Tensile strength vs $1 / D P$ for flax fibre at various temperatures and times. $D P$ for flax was not measured but rather was calculated using data from Ref. [12] using Eqs. (3, 6, 11) and (15) with the measured temperature history.

Table 4. $D P$ of flax fibre heat treated for five time periods and at $170^{\circ} \mathrm{C}$ using proposed model.

\begin{tabular}{|c|c|c|c|c|c|}
\hline $\begin{array}{c}\text { Consolidation } \\
\text { time [min] }\end{array}$ & $\begin{array}{c}\text { Tensile strength } \\
\text { of composites } \\
{[\mathrm{MPa}]}\end{array}$ & $\begin{array}{c}D P \text { of } \\
\text { matrix }\end{array}$ & $\begin{array}{c}\text { DP of } \\
\text { fibre }\end{array}$ & $\begin{array}{c}\text { Calculated } \\
\text { Tensile } \\
\text { strength of } \\
\text { matrix [MPa] }\end{array}$ & $\begin{array}{c}\text { Calculated } \\
\text { tensile } \\
\text { strength of } \\
\text { fibre [MPa] }\end{array}$ \\
\hline 15 & 276 & 746 & 1183 & 39 & 385 \\
\hline 30 & 234 & 514 & 975 & 30 & 334 \\
\hline 45 & 187 & 404 & 829 & 24 & 300 \\
\hline 60 & 166 & 252 & 474 & 16 & 237 \\
\hline 120 & 149 & 231 & 353 & 14 & 231 \\
\hline 180 & & & 721 & 21 & 277 \\
\hline
\end{tabular}

\subsection{Proposed model to predict the tensile strength of NFRP bio-composites}

The linear relationship proposed by Flory [9] (Eq. 14) is unrealistic for longer periods of time. As shown in Fig. 6, the trend of his model reaches to zero or negative values of the tensile strength after 180 minutes. To overcome this shortcoming, a new model is proposed here (Eqs. (16) and (18)) to predict the tensile strength for longer periods and ensure that the 
trend never goes below zero. The proposed model was used to predict the tensile strength of matrix and fibre (shown in Fig. 4 and 5 as 'proposed model', Eqs. (16) and (18)); subsequently it was used to predict the tensile strength of the flax/PLA bio-composite. The model results are also in agreement with our previous measurements [19] (for a different batch of materials) also shown in Fig. 6.

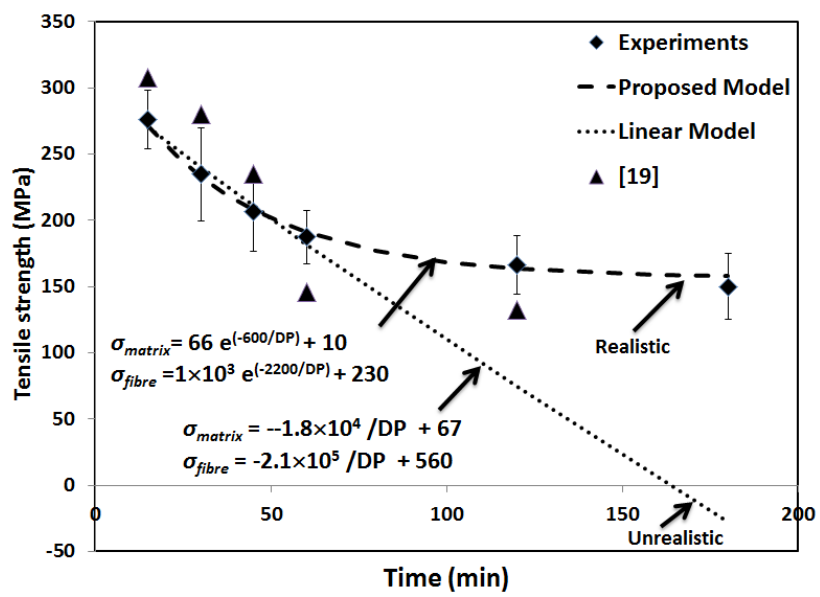

Fig. 6. Experimental data of the flax/PLA bio-composite and the prediction differences of the linear model and the proposed model

\section{Conclusions}

In this paper we introduced a link between the chemical degradation of NFRP bio-composite during thermal processing and their mechanical properties. To achieve this goal the following processes were taken into account:

i. Mechanical properties of the bio-composite can be calculated by estimating their relationship with the changes of $D P$ over the temperature and time. This relationship has separately been proposed for both matrix and fibre.

ii. The modulus of elasticity for both the flax fibre and for PLA may be assumed to be independent of the thermal processing.

iii. A linear relationship between strength and 1/DP, as proposed in the literature, was used to calculate the tensile strength of matrix and fibre, and for first time used to predict the mechanical properties of NFRP bio-composites.

iv. To predict the tensile strength of NFRP bio-composite, the linear model was neither reliable nor practical for extended periods of time; subsequently a new exponential model was proposed which is realistic and within $10 \%$ of errors. Thus, tensile strength of PLA can be predicted as a function of its temperature history during processing using Eqs. (4-6) and (16) and the fibre using Eqs. (3, 6, 10) and (18). 
Acknowledgments: The first author acknowledges the support of a Griffith University International Postgraduate Research Scholarship (GUIPRS and GUPRS).

\section{References}

[1] D. Plackett, T. Løgstrup Andersen, W. Batsberg Pedersen, L. Nielsen, Biodegradable composites based on L-polylactide and jute fibres, Composites Science and Technology, 63 (2003) 1287-1296. [2] B. Bax, J. Müssig, Impact and tensile properties of PLA/Cordenka and PLA/flax composites, Composites Science and Technology, 68 (2008) 1601-1607.

[3] K. Adekunle, S.-W. Cho, C. Patzelt, T. Blomfeldt, M. Skrifvars, Impact and flexural properties of flax fabrics and Lyocell fiber-reinforced bio-based thermoset, Journal of Reinforced Plastics and Composites, 30 (2011) 685-697.

[4] N. Graupner, A.S. Herrmann, J. Müssig, Natural and man-made cellulose fibre-reinforced poly (lactic acid)(PLA) composites: An overview about mechanical characteristics and application areas, Composites Part A: Applied Science and Manufacturing, 40 (2009) 810-821.

[5] S. Alimuzzaman, R.H. Gong, M. Akonda, Nonwoven polylactic acid and flax biocomposites, Polymer Composites, 34 (2013) 1611-1619.

[6] T. Yu, J. Ren, S. Li, H. Yuan, Y. Li, Effect of fiber surface-treatments on the properties of poly(lactic acid)/ramie composites, Composites Part A: Applied Science and Manufacturing, 41 (2010) 499-505.

[7] B. Baghaei, M. Skrifvars, M. Rissanen, S.K. Ramamoorthy, Mechanical and thermal characterization of compression moulded polylactic acid natural fiber composites reinforced with hemp and lyocell fibers, Journal of Applied Polymer Science, 131 (2014).

[8] H.M. Khanlou, W. Hall, M.T. Heitzman, J. Summerscales, P. Woodfield, Technical Note: On modelling thermo-chemical degradation of poly(lactic acid), Polymer Degradation and Stability, 134 (2016) 19-21.

[9] P.J. Flory, Tensile strength in relation to molecular weight of high polymers, Journal of the american chemical society, 67 (1945) 2048-2050.

[10] D. Rasselet, A. Ruellan, A. Guinault, G. Miquelard-Garnier, C. Sollogoub, B. Fayolle, Oxidative degradation of polylactide (PLA) and its effects on physical and mechanical properties, European Polymer Journal, 50 (2014) 109-116.

[11] L.M. Nicholson, K.S. Whitley, T.S. Gates, J.A. Hinkley, How molecular structure affects mechanical properties of an advanced polymer, (2000).

[12] J. Gassan, A.K. Bledzki, Thermal degradation of flax and jute fibers, Journal of Applied Polymer Science, 82 (2001) 1417-1422.

[13] M. Hallam, D. Cansfield, I. Ward, G. Pollard, A study of the effect of molecular weight on the tensile strength of ultra-high modulus polyethylenes, Journal of materials science, 21 (1986) 41994205.

[14] Y. Li, S. Moyo, Z. Ding, Z. Shan, Y. Qiu, Helium plasma treatment of ethanol-pretreated ramie fabrics for improving the mechanical properties of ramie/polypropylene composites, Industrial Crops and Products, 51 (2013) 299-305.

[15] P. Wambua, J. Ivens, I. Verpoest, Natural fibres: can they replace glass in fibre reinforced plastics?, composites science and technology, 63 (2003) 1259-1264.

[16] S. Ochi, Mechanical properties of kenaf fibers and kenaf/PLA composites, Mechanics of materials, 40 (2008) 446-452.

[17] O. Asumani, R. Reid, R. Paskaramoorthy, The effects of alkali-silane treatment on the tensile and flexural properties of short fibre non-woven kenaf reinforced polypropylene composites, Composites Part A: Applied Science and Manufacturing, 43 (2012) 1431-1440.

[18] A. Mechraoui, B. Riedl, D. Rodrigue, The effect of fibre and coupling agent content on the mechanical properties of hemp/polypropylene composites, Composite Interfaces, 14 (2007) 837-848. 
[19] H.M. Khanlou, P. Woodfield, J. Summerscales, W. Hall, Consolidation process boundaries of the degradation of mechanical properties in compression moulding of natural-fibre bio-polymer composites, Polymer Degradation and Stability, 138 (2017) 115-125.

[20] K. Van de Velde, E. Baetens, Thermal and mechanical properties of flax fibres as potential composite reinforcement, Macromolecular Materials and Engineering, 286 (2001) 342-349.

[21] P.E. Le Marec, L. Ferry, J.-C. Quantin, J.-C. Bénézet, F. Bonfils, S. Guilbert, A. Bergeret, Influence of melt processing conditions on poly (lactic acid) degradation: Molar mass distribution and crystallization, Polymer Degradation and Stability, 110 (2014) 353-363.

[22] O. Wachsen, K. Platkowski, K.H. Reichert, Thermal degradation of poly-l-lactide-studies on kinetics, modelling and melt stabilisation, Polymer Degradation and Stability, 57 (1997) 87-94.

[23] H. Yu, N. Huang, C. Wang, Z. Tang, Modeling of poly (L-lactide) thermal degradation: Theoretical prediction of molecular weight and polydispersity index, Journal of applied polymer science, 88 (2003) 2557-2562.

[24] A. Memon, A. Nakai, Fabrication and mechanical properties of jute spun yarn/PLA unidirection composite by compression molding, Energy Procedia, 34 (2013) 830-838.

[25] M.A. Sawpan, K.L. Pickering, A. Fernyhough, Flexural properties of hemp fibre reinforced polylactide and unsaturated polyester composites, Composites Part A: Applied Science and Manufacturing, 43 (2012) 519-526.

[26] H. Mohammad Khanlou, W. Hall, P. Woodfield, J. Summerscales, G. Francucci, The mechanical properties of flax fibre reinforced poly(lactic acid) bio-composites exposed to wet, freezing and humid environments, Journal of Composite Materials, 0 (2017) 1-16.

[27] M. Gupta, V. Deshmukh, Thermal oxidative degradation of poly-lactic acid, Colloid and Polymer Science, 260 (1982) 514-517.

[28] Y. Doi, Y. Kanesawa, M. Kunioka, T. Saito, Biodegradation of microbial copolyesters: poly (3hydroxybutyrate-co-3-hydroxyvalerate) and poly (3-hydroxybutyrate-co-4-hydroxybutyrate),

Macromolecules, 23 (1990) 26-31.

[29] G. Testa, A. Sardella, E. Rossi, C. Bozzi, A. Seves, The kinetics of cellulose fiber degradation and correlation with some tensile properties, Acta polymerica, 45 (1994) 47-49.

[30] A.S. Virk, W. Hall, J. Summerscales, Modulus and strength prediction for natural fibre composites, Materials Science and Technology, 28 (2012) 864-871.

[31] M.R. Hossain, M.A. Islam, A. Van Vuurea, I. Verpoest, Tensile Behavior of Environment Friendly Jute Epoxy Laminated Composite, Procedia Engineering, 56 (2013) 782-788.

[32] G. Sèbe, N.S. Cetin, C.A. Hill, M. Hughes, RTM hemp fibre-reinforced polyester composites, Applied Composite Materials, 7 (2000) 341-349.

[33] Y. El-Shekeil, S. Sapuan, K. Abdan, E. Zainudin, Influence of fiber content on the mechanical and thermal properties of Kenaf fiber reinforced thermoplastic polyurethane composites, Materials \& Design, 40 (2012) 299-303.

[34] M.S. Huda, L.T. Drzal, A.K. Mohanty, M. Misra, Effect of fiber surface-treatments on the properties of laminated biocomposites from poly (lactic acid)(PLA) and kenaf fibers, Composites Science and Technology, 68 (2008) 424-432.

[35] T. Yu, J. Ren, S. Li, H. Yuan, Y. Li, Effect of fiber surface-treatments on the properties of poly (lactic acid)/ramie composites, Composites Part A: Applied Science and Manufacturing, 41 (2010) 499-505.

[36] G. Mehta, L.T. Drzal, A.K. Mohanty, M. Misra, Effect of fiber surface treatment on the properties of biocomposites from nonwoven industrial hemp fiber mats and unsaturated polyester resin, Journal of applied polymer science, 99 (2006) 1055-1068.

[37] S. Das, A. Saha, P. Choudhury, R. Basak, B. Mitra, T. Todd, S. Lang, R. Rowell, Effect of steam pretreatment of jute fiber on dimensional stability of jute composite, Journal of Applied Polymer Science, 76 (2000) 1652-1661.

[38] N. Soatthiyanon, A. Crosky, M.T. Heitzmann, Comparison of experimental and calculated tensile properties of flax fibres, International Conference on Performance-based and Life-cycle Structural Engineering, School of Civil Engineering, The University of Queensland, 2015, pp. 116-120. 
